\title{
RANCANG BANGUN SISTEM INFORMASI PENILAIAN KINERJA KARYAWAN PT INKA(PERSERO) MENGGUNAKAN METODE EXTREME PROGRAMMING
}

\section{Ignatius Bagas Kurniawan ${ }^{1}$}

${ }^{1}$ Universitas PGRI Madiun

\section{Article Info:}

Dikirim: 21 Desember 2020

Direvisi: 25 Desember 2020

Diterima: 30 Desember 2020

Tersedia Online: 31 Desember 2020

Penulis Korespondensi: Ignatius Bagas Kurniawan

Unipma, Madiun, Indonesia Email: gassiebagas@gmail.com

\begin{abstract}
Abstrak: Teknologi saat ini semakin berkembang pesat, setiap perusahaan memiliki sistem informasi yang dapat meningkatkan ke-efektifitasan kinerja karyawannya. Sama pada halnya di PT INKA (Persero), Sistem Penilaian Kinerja Karyawan (SPIKER) yang dibuat dapat meningkatkan ke-efektifitasan kinerja karyawannya, yang sebelumnya secara manual dan objektif menjadi otomatis dan efektif setelah pembuatan Sistem Informasi ini. Sistem Informasi ini menilai kinerja Karyawan dalam beberapa aspek. Diantaranya adalah nilai output,nilai atasan,nilai learning,dll. Setiap aspek tersebut memiliki presentase atau bobot yang berbeda-beda. Sistem informasi dibuat menggunakan Bahasa pemograman PHP(Hypertext Preprocessor), HTML(Hypertext Markup Language),dan CSS (Cascading Style Sheets). Menggunakan metode Extreme Programming yang membuat sistem informasi ini tepat guna atau sesuai dengan kebutuhan yang diperlukan.
\end{abstract}

Kata kunci: extreme programming; sistem informasi; penilaian kinerja.

\begin{abstract}
Technology is currently growing rapidly, every companies has an Information system that can improve the effectiveness of employee performance. Similar to PT INKA (Persero),Penilaian Kinerja Karyawan (SPIKER) was created to increase the effectiveness of employee performance, which previously manually and objectively became automatic and becoming more effective after the creation of this Information System. This information system appraise employee performance in several aspects. Those aspects are output value, superior value, learning value, etc. Each of these aspects has a different percentage of weight. The information system was created using the PHP (Hypertext Preprocessor) programming language, HTML (Hypertext Markup Language), and CSS (Cascading Style Sheets). Using Extreme Programming method which makes this information system efficient or in accordance with the required needs.
\end{abstract}

Keywords: extreme programming; information system; employee performance assessment. 


\section{PENDAHULUAN}

Perkembangan teknologi saat ini menjadi hal yang sangat penting hampir di seluruh sektor. Adanya era revolusi industri 4.0, seperti menjadi tuntutan bahwa segala sektor kehidupan saat ini harus mampu beradaptasi dan mampu mengikuti perkembangan teknologi. Sebagai contoh yakni sektor perusahaan industri transportasi yang dinilai mempunyai nilai lebih dalam hal kontribusi kepada masyarakat. Departemen pengembangan perusahaan menjadi salah satu bagian perusahaan yang sangat potensial dan berperan penting bagi tercapainya tujuan perusahaan serta dalam upaya mendukung kemajuan perusahaan. Salah satunya melalui sistem perencanaan dan penilaian kinerja karyawan yang baik dengan berbasis teknologi. Pada kesempatan kali ini, upaya tersebut terealisasikan pada perencanaan rancang bangun sekaligus pengembangan Sistem Informasi Penilaian Kinerja Karyawan PT INKA (Persero) yang dinamakan SPIKER PT INKA (Persero). Pada implementasi rancang bangun SPIKER PT INKA (Persero), Departemen Pengembangan Perusahaan PT INKA (Persero) merupakan obyek pertama yang nantinya terlibat dalam uji coba penggunaan SPIKER PT INKA (Persero).

Departemen Pengembangan Perusahaan merupakan salah satu departemen yang terdapat di PT INKA (Persero). Departemen Pengembangan Perusahaan PT INKA (Persero) memiliki 3 unit di dalamnya untuk menunjang tugas dan kinerja departemen. Salah satunya adalah Unit Perencanaan dan Penilaian Kerja yang bertugas untuk menilai kinerja karyawan. Penerapan teknologi dan sistem informasi sudah masuk dan sudah diterapkan di PT INKA (Persero) khususnya yakni pada Unit Perencanaan dan Penilaian Kerja pada Departemen Pengembangan Perusahaan. Namun, tidak semua aspek telah melibatkan teknologi sistem informasi. Dalam penilaian kinerja karyawan terdapat parameter yang menjadi tolak ukur penilaian yang terdiri dari 5 aspek. 5 aspek tersebut adalah Output atau Capaian Kinerja, Penilaian Atasan, Learning atau Semangat Belajar, Kedisiplinan, dan 5R (Ringkas, Rapi, Resik, Rawat, dan Rajin). Presentase untuk tiap-tiap aspek antara lain $70 \%$ untuk nilai output, $10 \%$ untuk nilai atasan, $10 \%$ untuk nilai learning, 5\% untuk nilai kedisiplinan, dan 5\% untuk nilai 5R.

Penerapan penilaian kinerja karyawan di PT INKA (Persero) memiliki beberapa kendala di antaranya yakni belum adanya integrasi antar aspek penilaian, sehingga masing-masing aspek penilaian menggunakan platform yang berbeda-beda. Contohnya pada aspek penilaian kedisiplinan menggunakan aplikasi INKA Mobile, aspek penilaian learning menggunakan aplikasi I Knows, sedangkan aspek Output, Penilaian Atasan, dan 5R tidak menggunakan platform apapun. Sehingga belum ada integrasi yang baik dari masing-masing aspek penilaian.

Dari permasalahan yang dihadapi Departemen Pengembangan Perusahaan PT INKA (Persero) dapat disimpulkan bahwa penerapan teknologi informasi dapat dikatakan sudah diterapkan, namun belum ada keseragaman sistem dan integrasi yang baik antar 5 aspek penilaian. Sehingga, adanya permasalahan tersebut memunculkan ide untuk membangun sistem informasi penilaian kinerja karyawan dengan 5 aspek standar penilaian. i bagian awal pendahuluan, Penulis harus menyajikan latar belakang yang memadai. Pada bagian berikutnya harus mneyajikan, survei literatur singkat untuk menyampaikan solusi / metode yang ada, menunjukkan mana yang terbaik dari penelitian sebelumnya dan untuk menunjukkan keterbatasan utama dari penelitian sebelumnya.

\section{TINJAUAN PUSTAKA}

\subsection{Sistem Informasi}

Sistem informasi merupakan sebuah gabungan antara orang (people), perangkat lunak (software), perangkat keras (hardware), sumber data (data resources), jaringan komunikasi (communication network), dan kebijakan dan prosedur (policies and procedures) [1]. Komponen sistem informasi tersebut dapat ditunjukkan pada Gambar 1 .

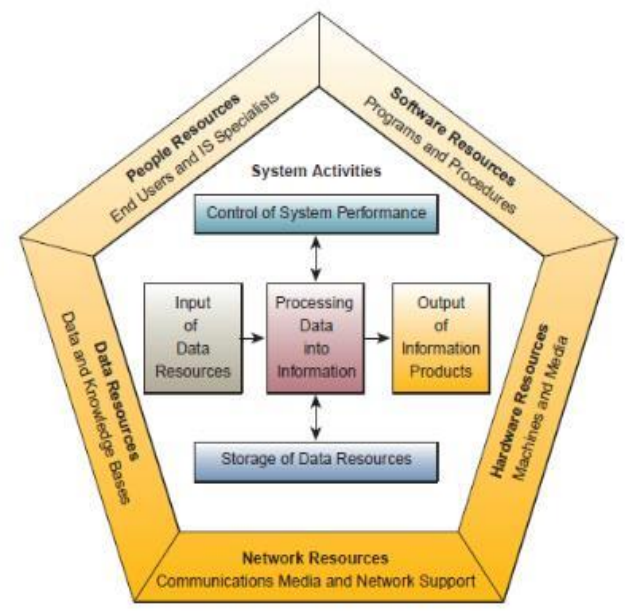

Gambar 1. Komponen Sistem Informasi 


\subsection{Penilaian Kinerja}

Sebelum menjelaskan tentang apa itu penilaian kinerja, terlebih dahulu sebaiknya perlu untuk dipahami tentang apa itu kinerja dan mengapa kinerja perlu untuk dinilai. Kinerja diartikan sebagai suatu bangunanyang multi dimensi, dimana kinerja tidak dapat diukur atas dasar satu faktor atau dimensi saja [2].

\section{$2.3 \quad M y S Q L$}

Merupakan software yang tergolong database server dan bersifat Open Source. Open Source menyatakan bahwa software ini dilengkapi dengan source code (kode yang dipakai untuk membuat MySQL), selain itu tentu saja bentuk executable-nya atau kode yang dapat dijalankan secara langsung dalam sistem [2].

\subsection{PHP}

PHP (akronim dari Hypertext Preprocessor) adalah bahasa pemograman intrepeter yaitu proses penerjemahan baris kode sumber menjadi kode mesin yang dimengerti oleh computer secara langsung pada saat baris kode dijalankan sehingga web menjadi dinamis. PHP yang merupakan bahasa pemrograman berbasis web yang memiliki kemampuan untuk memproses data dinamis.

\subsection{SQL Injection}

SQL Injection merupakan salah satu Teknik hacking yang sebenarnya bukanlah hal baru. Teknik yang digunakan dalam SQL injection adalah dengan menginput perintah-perintah standar dalam SQL seperti create, insert, update, drop, alter, union dan select secara langsung pada form yang terdapat pada website. Serangan injeksi terjadi ketika seseorang dengan sengaja menggunakan saluran yang tidak sah untuk mengirim perintah SQL berbahaya ke server database [3].

\section{METODOLOGI PENELITIAN}

Tahapan - tahapan yang dilakukan dalam pengembangan sistem informasi penilaian kinerja karyawan en dengan menggunakan model Extreme Programming sebagai berikut:

a) Perencanaan, pada tahapan ini peneliti melakukan perencanaan berdasarkan requirements user dimana dilakukan pengaturan prioritas terhadap permintaan user berdasarkan skala prioritas dan waktu pembangunan sistemnya. Pada perencanaan ini akan dilakukan pengecekan kembali dengan mempertimbangkan resiko yang dihasilkan.

b) Desain, pada tahapan desain dilakukan proses iterasi selama pembangunan dimana proses analisis dan desain akan menghasilkan beberapa $U M L$ antara lain use case diagram, activity diagram, sequence diagram dan class diagram oleh system analyst. Pada tahapan ini sudah membangun prototype awal sebagai gambaran sistem yang akan dibangun.

c) Coding (pengkodean sistem), dalam tahap ini prototype yang sudah disepakati akan diterjemahkan kedalam pemrograman dengan menggunakan PHP, HTML 5, CSS untuk tampilan antarmuka (User Interface) dan database MySQL.

d) Pengujian sistem, sistem selesai dibangun dan selanjutnya akan dilakukan proses pengujian sistem oleh Senior Manager PT INKA (Persero).

\section{ARSITEKTUR DATA}

Pada arsitektur data akan dijelaskan mengenai integrasi data yang ada pada sistem informasi penilaian kinerja karyawan PT INKA (Persero). Sistem tersebut lebih menekankan pada relasi yang terjadi antar aktivitas. Adapun gambaran relasi database dan aktivitas dalam pengembangan sistem informasi penilaian kinerja karyawan PT INKA (Persero) adalah sebagai berikut :

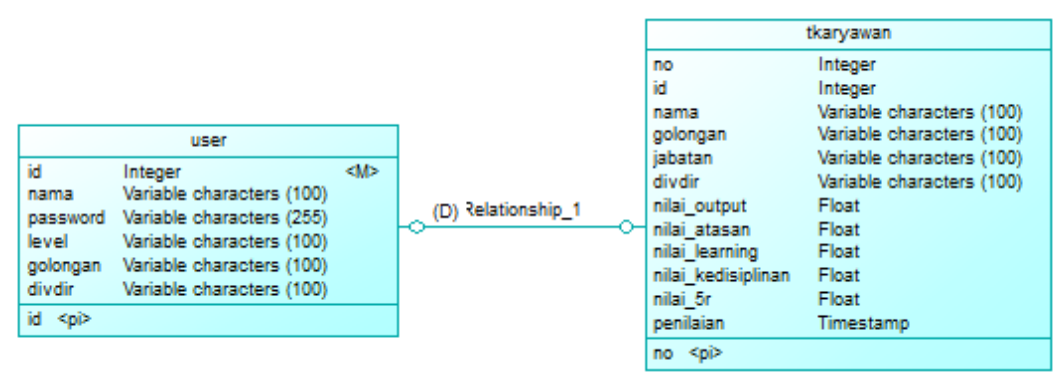

Gambar 2. Arsitektur Data Spiker INKA 
Pada perancangan arsitektur data, sistem penilaian kinerja karyawan PT INKA (Persero) masih menggunakan RDBMS open source yaitu Mysql. Arah pengembangan arsitektur data lebih mengutamakan efektivitas proses dan waktu dalam mengelola data. Lalu diperlukannya analisis lebih lanjut agar sistem dapat berkembang secara terus menerus.

\section{ARSITEKTUR TEKNOLOGI} berikut :

Pembuatan arsitektur teknologi sistem penilaian kinerja karyawan PT INKA (Persero) adalah sebagai

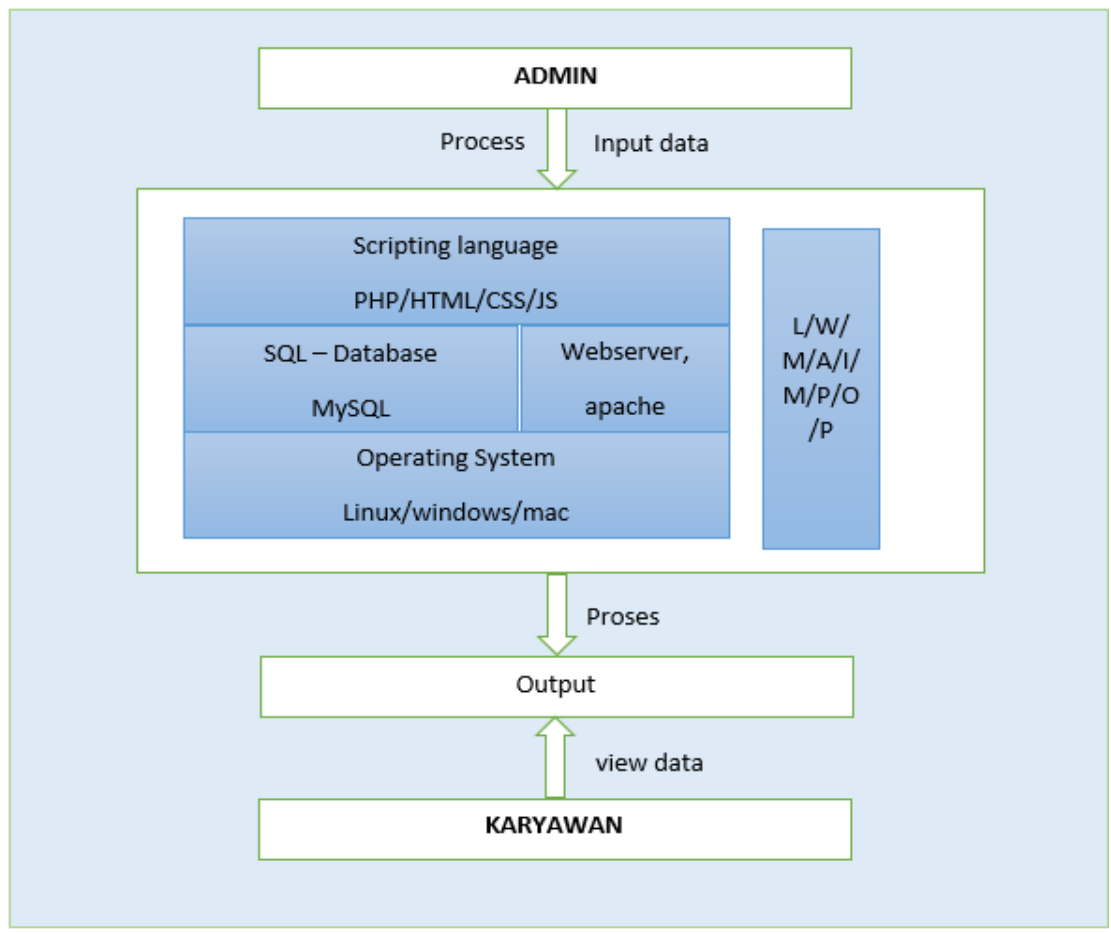

Gambar 3. Arsitektur Teknologi

\subsection{User}

User dapat menggunakan berbagai macam web browser untuk mengakses sistem penilaian kinerja karyawan seperti google chrome, mozilla firefox, opera, serta web browser lainnya.

\subsection{Web Server}

Web server diperlukan bagi pengguna browser untuk melakukan request dan response terhadap file komponen website. Apache merupakan web server yang merupakan standar yang diperlukan oleh MySQL.

\subsection{Scripting Language}

Menggunakan Bahasa pemograman HTML 5, PHP ver 7, CSS, serta Java Script. Sistem diproteksi dari serangan SQL Injection karena pengaplikasian prepare statement dalam query PHP serta penggunaan hash sha 256 pada proteksi password.

\subsection{SQL Database}

Sistem penilaian kinerja karyawan menggunakan $M y S q l$ untuk menyimpan dan mengelola data yang ada. MySql merupakan salah satu dari banyak Relational Database Management System (RDBMS) softwares yang dapat digunakan secara gratis/open source. 


\section{HASIL DAN PEMBAHASAN}

Implementasi Sistem Informasi Peilaian Kinerja Karyawan PT INKA(Persero) merupakan tahap coding sistem sesuai dengan rancangan yang telah dibuat sebelumnya. Coding sistem menggunakan Bahasa pemograman HTML5, CSS, JavaScript, dan AJAX. Berikut adalah tampilan tiap page dan fungsi - fungsi system:

\subsection{Halaman utama}

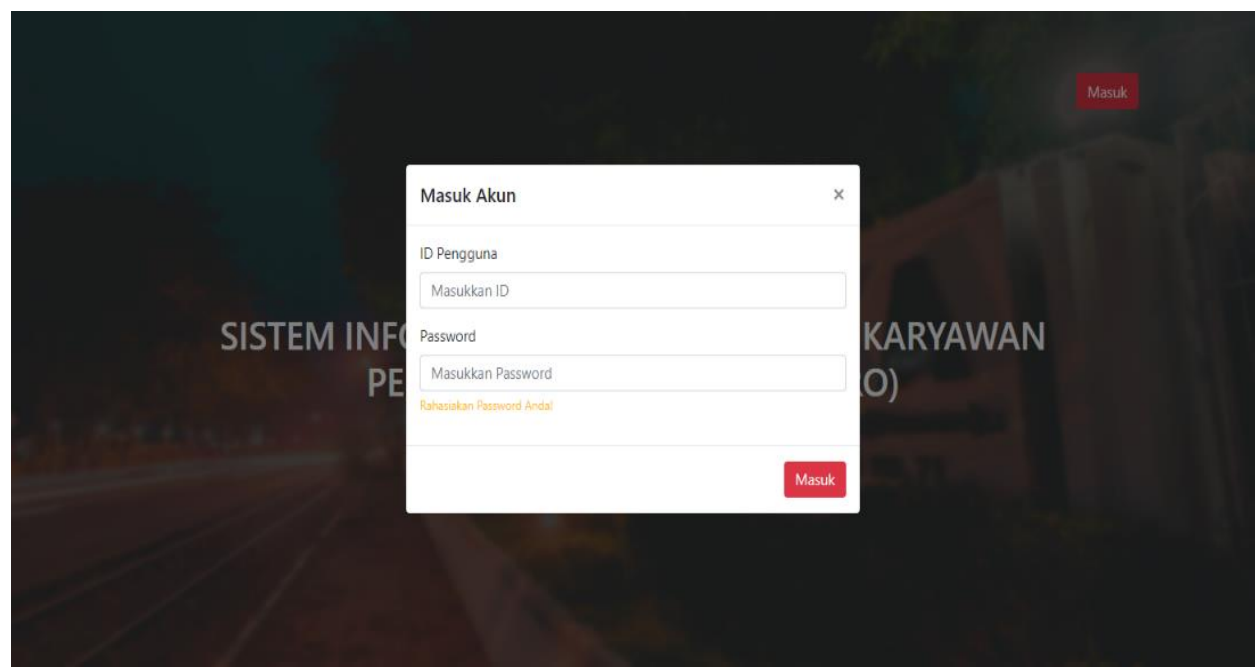

Gambar 4. Halaman Home (login)

Halaman utama pada gambar diatas merupakan halaman bila sebuah user mengakses website, user akan otomatasi ter-redirect pada halaman utama dan dapat melakukan login menggunakan akun yang telah dibuat admin. User tidak dapat meregistrasi akun tanpa admin. Password pada modal login ini terproteksi oleh hash sha256.

\subsection{Halaman User}

Pada halaman user terdapat sebuah table yang memberikan informasi berupa nama user yang login sesuai dengan sessionnya, copy data pada tabel, export data dalam bentuk excel maupun pdf. Terdapat pagination pada tabel agar data tersusun dengan rapi.

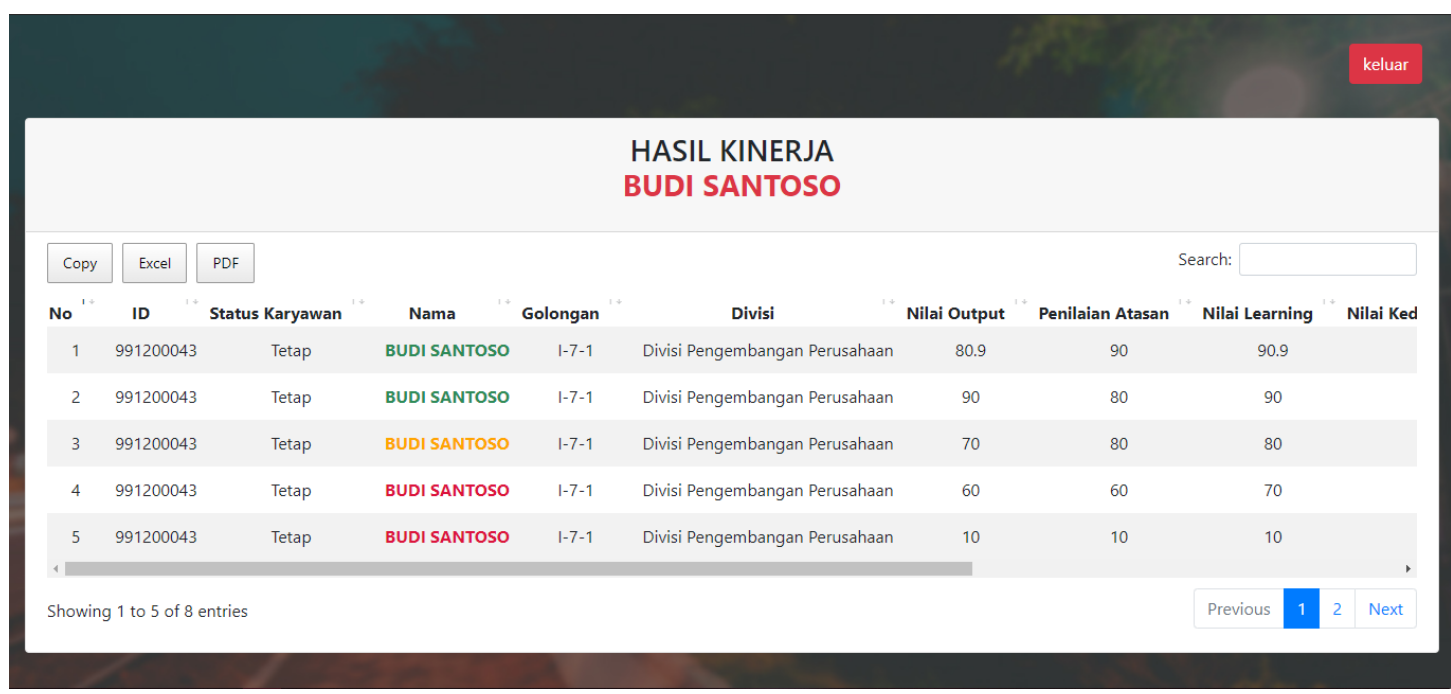

\section{Gambar 5. Halaman User}

Data data yang ada pada tabel berupa nomor data, ID User,Status karyawan, Nama user,Golongan, divisi, Nilai output, Penilaian atasan, Nilai learning, Nilai kedisiplinan, Nilai 5R, Hasil (Average setiap nilai), IKK, Keterangan dan juga Periode. 


\subsection{Halaman Admin}

Halaman admin hanya dapat diakses oleh user ber-level admin. User yang tidak memiliki akses akan langsung ter-redirect ke halaman home atau halaman utama(Bila memaksakan masuk).
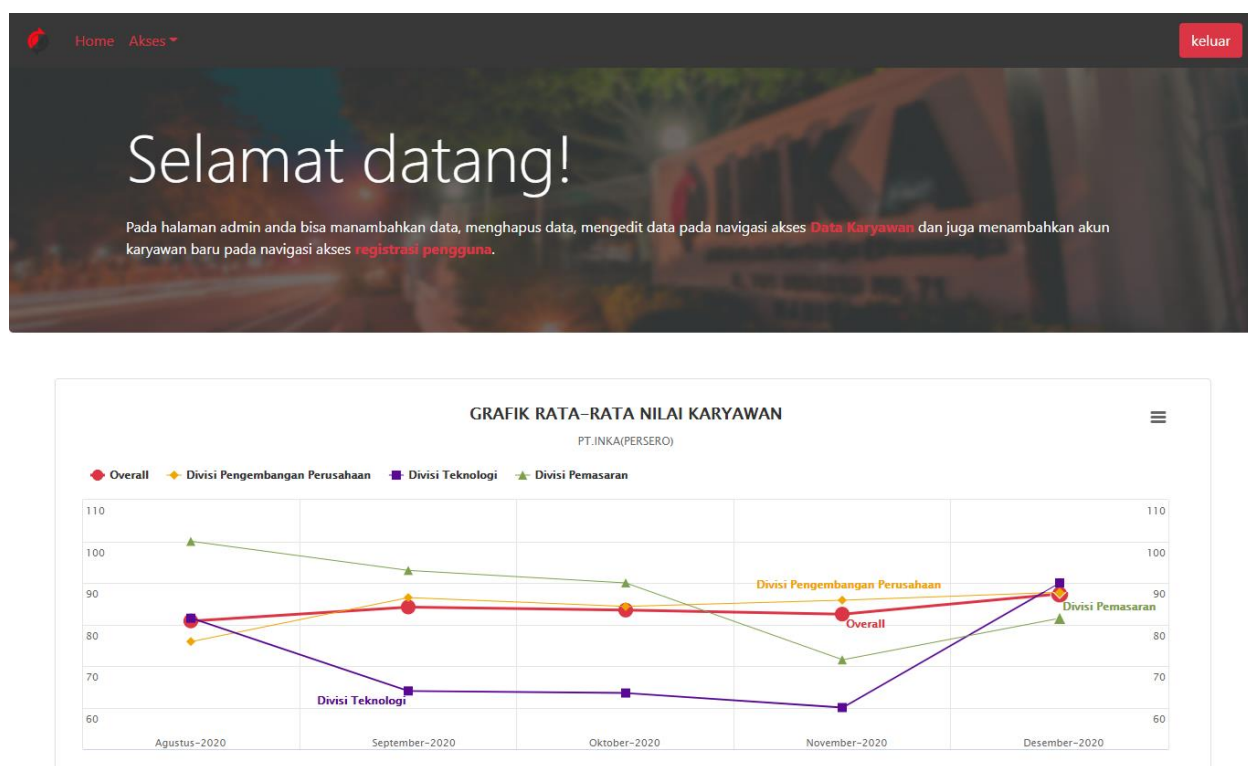

Gambar 6. Halaman Admin

Terdapat berbagai macam fungsi, pada halaman ini seorang admin dapat melihat grafik rata rata, melihat seluruh info kinerja karyawan. Sama dengan halnya halaman user, table yang tersedia juga berisi berupa nomor data, ID User,Status karyawan, Nama user,Golongan, divisi, Nilai output, Penilaian atasan, Nilai learning, Nilai kedisiplinan, Nilai 5R, Hasil (Average setiap nilai), IKK, Keterangan dan juga tanggal input.

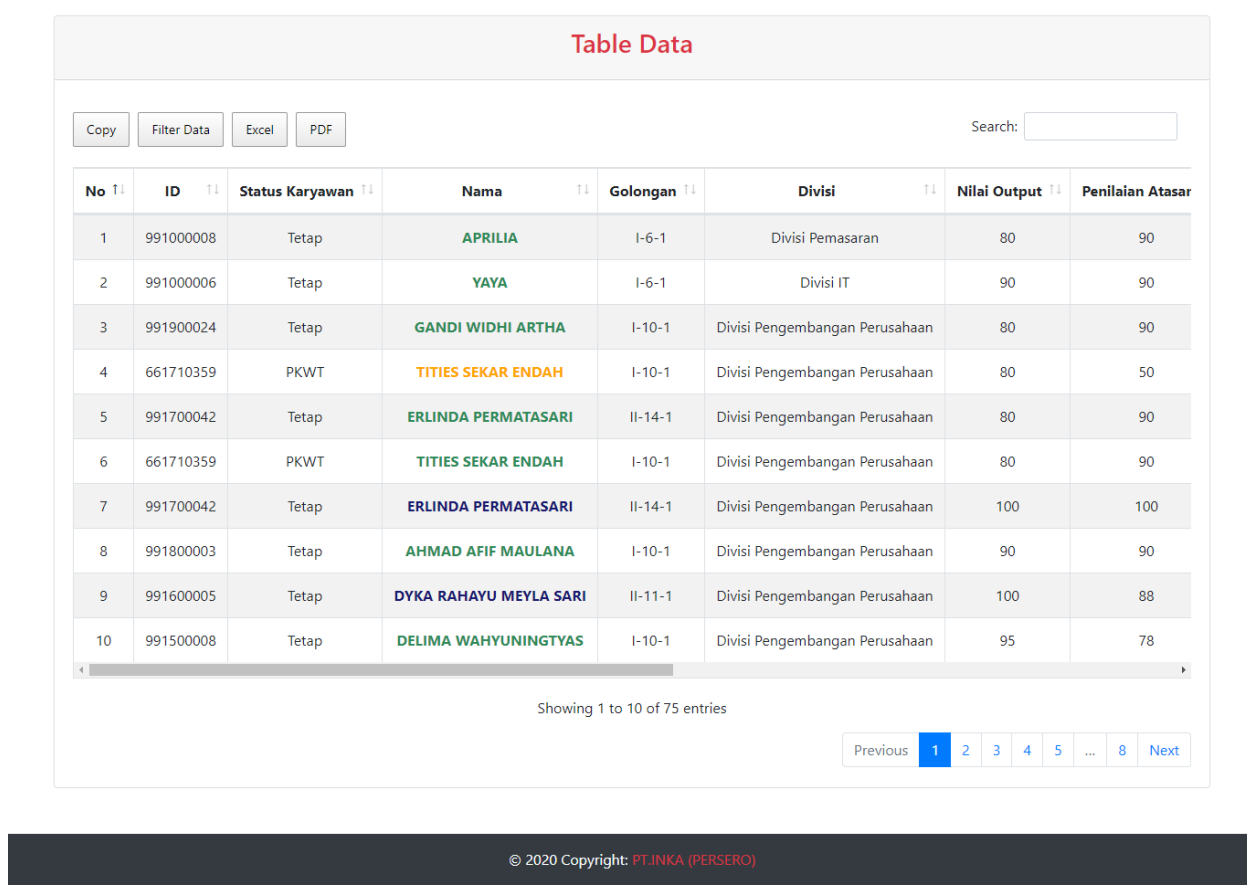

Gambar 7. Halaman informasi Admin

\subsection{Menu Akses Data}

Pada menu akses data, admin dapat menambah data data user. Admin hanya dapat menambahkan data user yang telah ter-registrasi. Hal ini dapat diperiksa pada kolom ID user yang akan terisi otomatis bila user telah tersedia/ter-registrasi. 


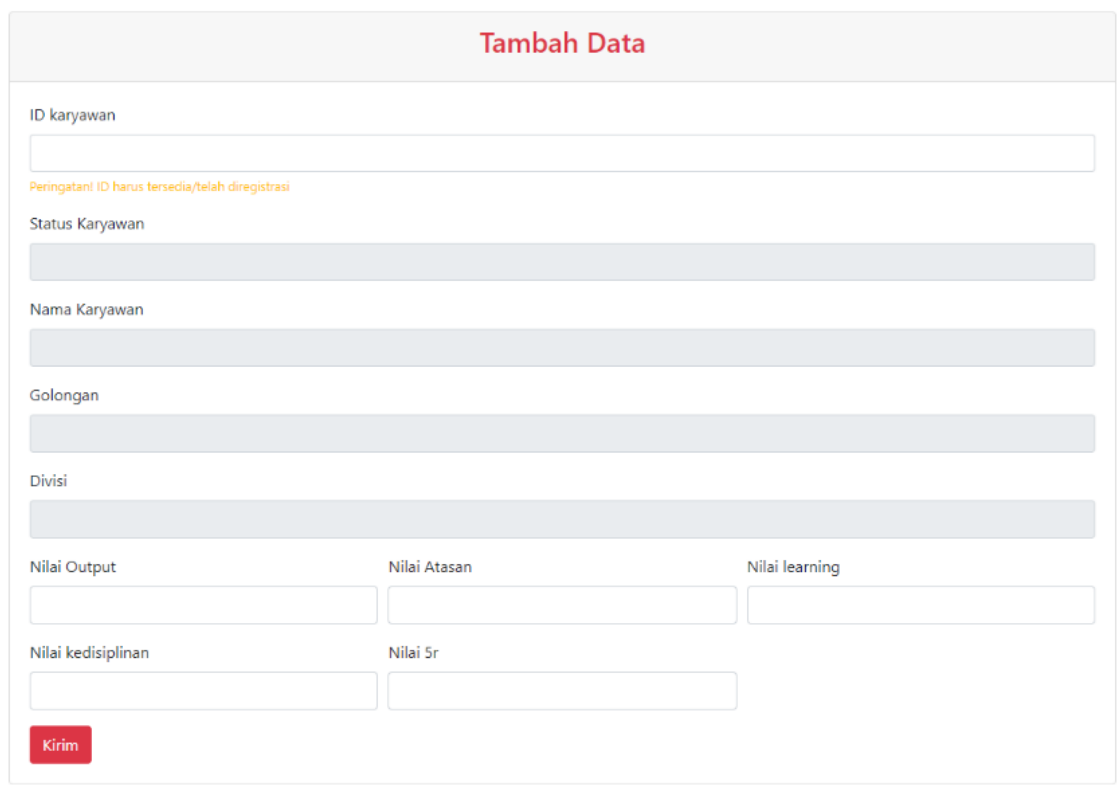

\section{Gambar 8. Tambah data}

Admin juga dapat menambahkan data menggunakan fungsi import excel. Pada import excel admin dapat menambahkan data dari excel yang telah diupload.

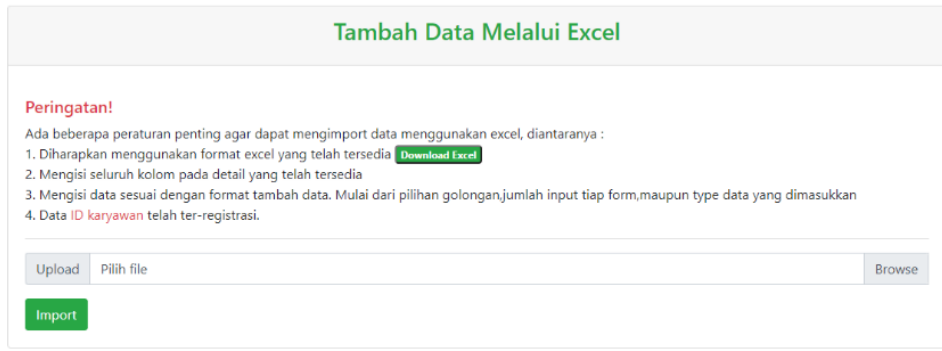

\section{Gambar 9. Halaman Tambah Data(Excel)}

Selain itu admin memiliki wewenang untuk edit dan hapus data user sesuai dengan divisinya masing masing

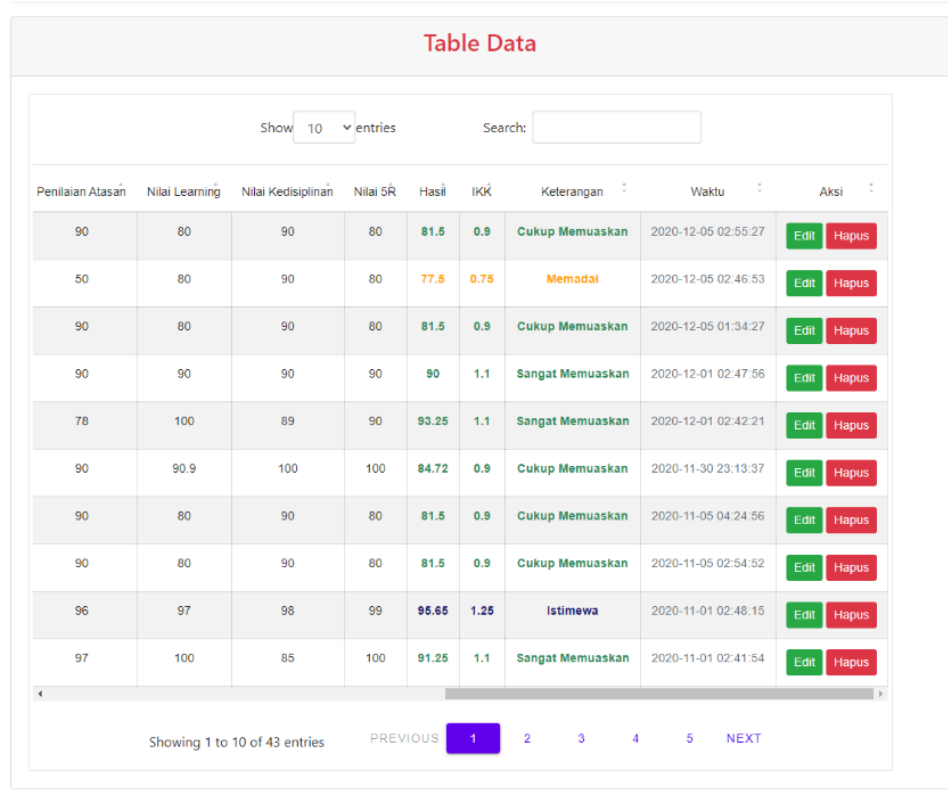




\subsection{Menu Akses Register User}

Pada menu register, admin dapat menambahkan user baru. Admin akan gagal menambahkan user baru bila ID karyawan telah tersedia/dipakai.

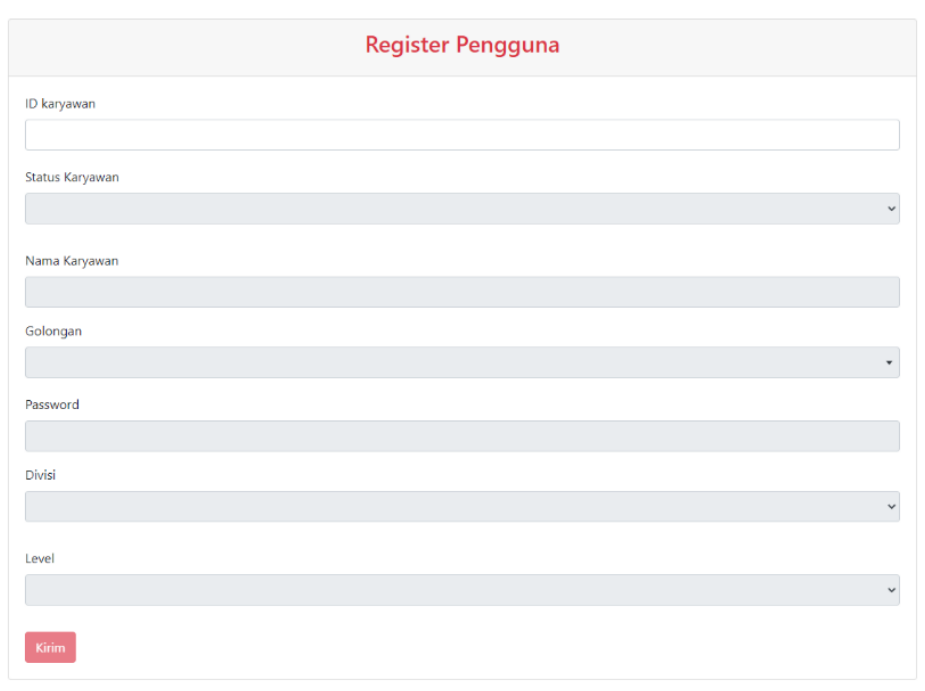

Gambar 11. Halaman Register Pengguna

\section{KESIMPULAN}

Berdasarkan penelitian yang dilakukan dalam perancangan Sistem Informasi Penilaian Kinerja Karyawan PT INKA(Persero), dapat disimpulkan bahwa Sistem Informasi yang dibuat ini dapat mempermudah dalam penilaian kinerja karyawan PT INKA. Tata kelola diperlukan untuk membuat formulasi kebijakan. Implementasinya agar dapat dipastikan adanya integrasi terhadap kebutuhan PT INKA yang ada. Sehingga, pengembangan sistem penilaian nantinya selaras dengan kebutuhan tersebut. Fokus perancangan tata kelola sistem penilaian kinerja karyawan ada pada:

a) Sistem informasi sesuai dengan kebutuhan perusahaan yang telah dirumuskan.

b) Sistem informasi dapat menambah nilai keefektivitasan dalam penilaian kinerja karyawan dengan menambahkan beberapa akun pengguna untuk menerapkan sistem informasi diseluruh karyawan di PT INKA (Persero).

\section{DAFTAR PUSTAKA}

[1] Wahyudi, I., Bahri, S., \& Handayani, P. (2019). Aplikasi Pembelajaran Pengenalan Budaya Indonesia. V(1), 135-138. https://doi.org/10.31294/jtk.v4i2

[2] Ricoida, D. I., Denny, D., \& Santoso, S. (2019). Sistem Informasi Penilaian Kinerja Dosen Dengan Metode Extreme Programming (Studi Kasus: STMIK MDP). JATISI (Jurnal Teknik Informatika Dan Sistem Informasi), 5(2), 216-225. https://doi.org/10.35957/jatisi.v5i2.147.

[3] Djayali, A. D. (2020). Analisa Serangan SQL Injection pada Server pengisian Kartu Rencana Studi ( KRS ) Online. 1(1), 1-9. 